\title{
Experimental Legislation with Reference to the Crab and Lobster Fisheries of the East Coast of Britain.
}

\author{
By
}

\author{
Professor Alexander Meek, D.Sc. \\ Dove Marine Laboratory, Cullercoats.
}

With Seven Figures in the Text.

So large a demand has been made for copies of the recently published paper on the effects of legislation on the crab fisheries of the East Coast* that a new paper is necessary. A summary is given of the previous paper and the figures have been reproduced. For convenience of reference they are arranged and numbered as before. The opportunity has been taken to give a review of the attempts to improve the lobster fisheries by legislation.

\section{Crab.}

The Oyster, Crab and Lobster Act of 1877 gives a size limit of $4 \frac{1}{4}$ jn., and protects the soft and berried crab. But, as will be seen from Figure 1 (p. 756 ), this apparently adequate protection was not sufficient to prevent a decline in the fishery on the East Coast in general. It has long been recognised that the winter fishing for crabs is a very destructive one, and two Committees attempted early to strengthen the Act by local legislation.

The Eastern Committee (Norfolk and Lincolnshire) passed in 1894 a by-law prohibiting the catching of soft or white-footed crabs from 1st November to 30 th June each year. The by-law has had the effect of stopping the winter fishing, the crab-pots not being brought into use until February or even March as a rule. It may be regarded as conferring a close time during the season that soft crabs are prevalent along the coast.

The North-Eastern Committee (Humber to Tyne) passed a by-law which was in operation during the years 1896 to 1906 when it was repealed. This by-law gave a close time to the crab fishery between 1st September and 31st January each year.

Much later, after a great deal of enquiry and investigation, the Northumberland Committee (Berwick to Tyne) similarly passed a by-law

* 1924. Trans. Nat. Hist. Soc. of Northumberland, Durham and Newcastle-upon-Tyne. New Ser., Vol. VI, Part 1, p. 63.

NEW SERIES.-VOL. XIII. No. 4. OCTOBER, 1925. 


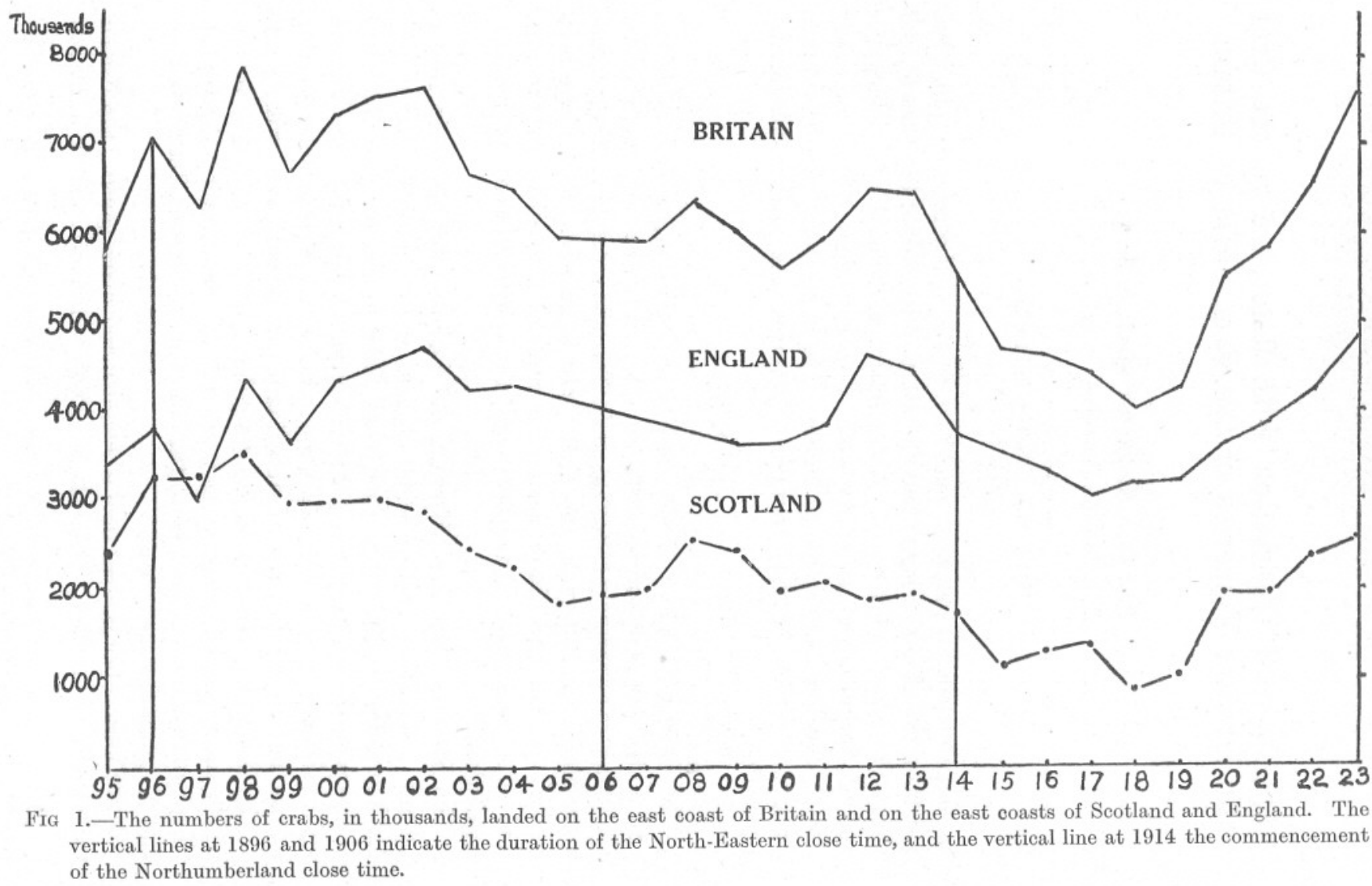
of the Northumberland close time. 
which gave a close time to the fishery from 1st October to 31st December in each year.

In each case the by-law is based on what every fisherman knows to be a fact that fishing during the season immediately succeeding the casting of the shell (ecdysis) is a destructive one. The aim of the legislation, in short, is to protect the fishery from the effects of destructive fishing.

The legislation in the Eastern district has been so long in force that it offers no figures for comparison. But, as will be seen from Figure 3 (p. 759), the catches have been maintained at a fairly constant level during the whole period.

Fortunately, in the case of the other two districts, the legislation has been in operation only for a limited period, and the effects may be readily ascertained. The North-Eastern Committee attempted a drastic remedy by closing the fishery for five months. The fishermen of the district from 1896 to 1906 were allowed to fish for seven months, and since 1906 have been permitted to fish all the year if they wished. The annual catches are displayed in Figure 2 (p. 758), and they indicate that despite the restricted period of fishing during the years in question-marked in the figure by vertical lines - the landings steadily improved, although the returns for the rest of the east coast of England exhibited a decrease. Since the by-law was withdrawn the fishery has followed the rest of the East Coast closely until the end of the period, when the figures sank below those of the rest of the East Coast.

Northumberland, as Figure 4 (p. 761) plainly shows, was undergoing a steady decrease during the greater part of the years under consideration. The decrease persisted during the years of the war-until 1918-when a rapid improvement took place, culminating in the year 1922. The delay in the improvement is much greater than that experienced by the NorthEastern Committee, and it does not appear to be due to the war. The fishery had declined so seriously that some years had to elapse before the protection began to take effect. The results of the two experiments in neighbouring districts at different periods become more clear when the two districts are compared, as is done in Figure 5 (p. 762). At the beginning of the period the two districts were landing about the same numbers each, and it is again at the end of the period that the catches in the two districts have become more equal.

The conclusion is warranted, therefore, that legislation designed to give protection during a period of destructive fishing produces good results.

Marking experiments have shown that the crab population as a whole is stationary, migrating seasonally into deep water in the winter and into shallow water in the summer. The larval stages are pelagic, and undergo a denatant, that is to say a down-current migration. The districts are related by current, and it follows that protection in one district will tend 


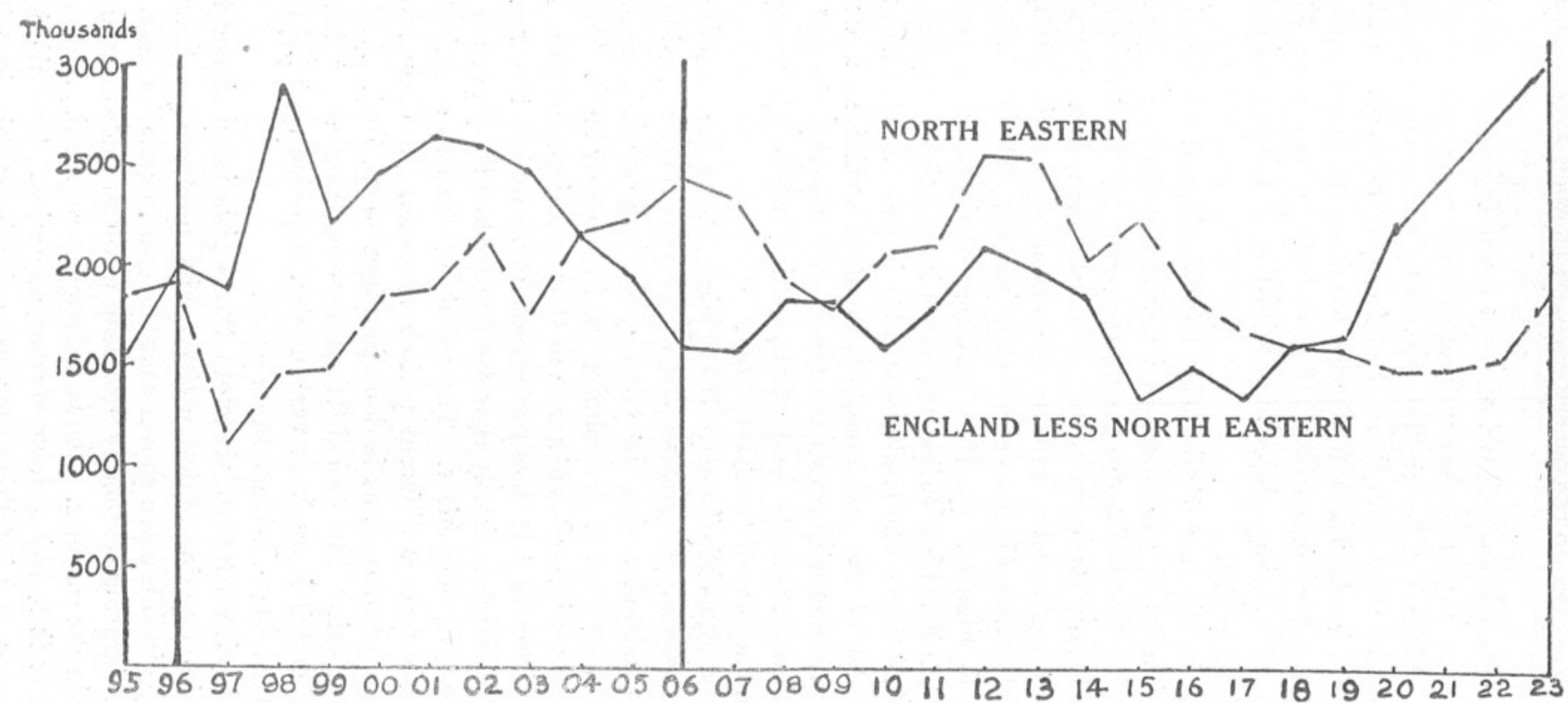

蜔

Fic 2.-The numbers of crabs, in thousands, landed on the east coast of England, less those landed in the district of the North-Eastern Committee, which latter are also shown. 


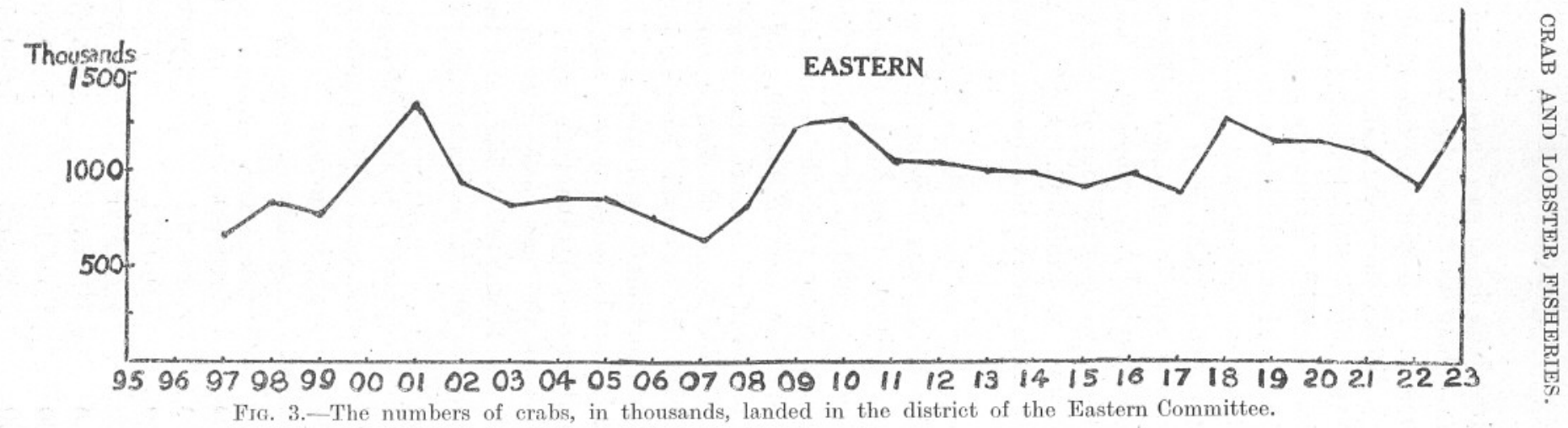


to benefit the district which lies down-current from it. Again, the female crabs, when they are about to become berried, migrate contranatantly, that is to say up-current. A district therefore which is protected may be expected to benefit a district on the contranatant side.

This interrelationship of the districts around our shores makes it desirable that the legislation which has been proved to be productive should be made uniform. There does not seem to be much, if any, difference in the season of casting or ecdysis, nor as to the time required for converting the soft or white-footed crab into a marketable crab around our coasts. But the seasons vary in a manner which has not yet been explained as to the time required for hardening. Last year, for example, the east coast of Britain was occupied for an extraordinarily long period by crabs in the process of hardening. This year, 1925, the reports indicate that the crabs on the Northumberland coast are plentiful and in good condition.

The effects of the contranatation of the berried females may be roughly estimated in the case of Northumberland. The average catch for the years $1895-1924$ was $1,155,000$. The marking experiments indicated that the fishermen were liable to catch 27 per cent of the population of adult crabs. If we assume, therefore, that the population is about $4,000,000$, the females would number about $2,080,000$. Of the females, about 14 per cent migrate each year to the north, most entering Scottish waters ; most coming to rest in the Eyemouth district, but spreading generally along the coast from Berwick to Banff. Keeping in mind that many of the southern crabs of Northumberland would, reach only the northern part of the county, it may be gathered that Scotland gains each year from Northumberland some 250,000 female crabs. The fact is, at any rate, that the catches on the east coast of Scotland since 1918 have undergone a notable rise (Figure 6, p. 763), and the improvement appears to be due to some extent to the improvement in Northumberland, with which it is coincident.

The inference receives support from the differences exhibited by the statistics in the districts to the south of Northumberland. The following table gives the landings of crabs in the four districts from 1918 to 1924 ; the districts are arranged in succession from north to south.

$\begin{array}{lcccr} & \text { Eyemouth. } & \text { Northumberland. } & \text { North Eastern. } & \text { Eastern. } \\ 1918 & 208,700 & 440,620 & 1,573,730 & 1,332,400 \\ 1919 & 223,700 & 626,859 & 1,560,612 & 1,200,200 \\ 1920 & 454,600 & 1,040,454 & 1,457,885 & 1,192,000 \\ 1921 & 678,800 & 1,211,930 & 1,457,777 & 1,126,000 \\ 1922 & 756,600 & 1,780,595 & 1,505,853 & 957,000 \\ 1923 & 760,900 & 1,594,437 & 1,840,793 & 1,324,400 \\ 1924 & 769,500 & 1,286,563 & 1,840,912 & 1,551,000\end{array}$




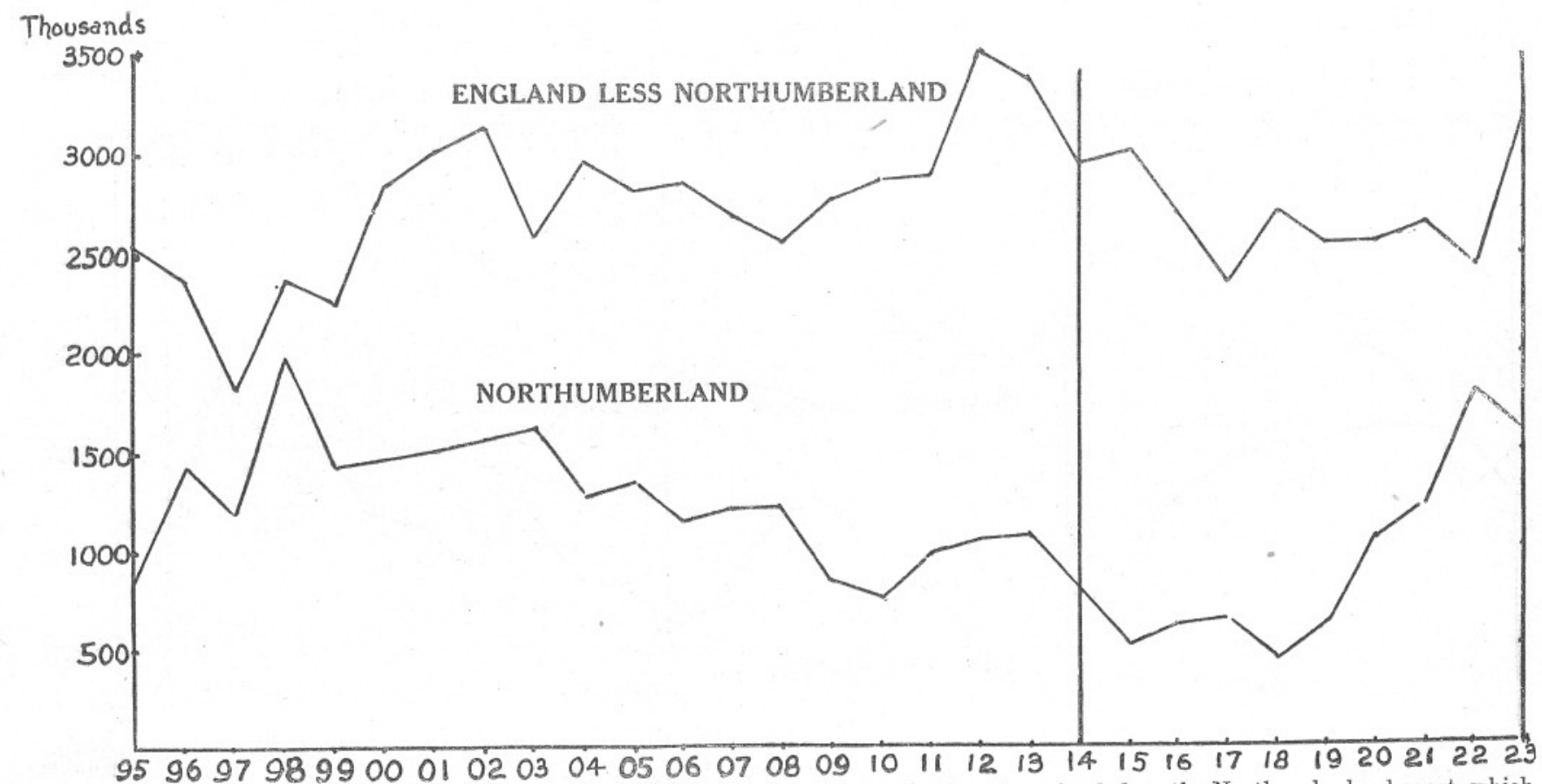

Fra. 4. latter are also shown. 


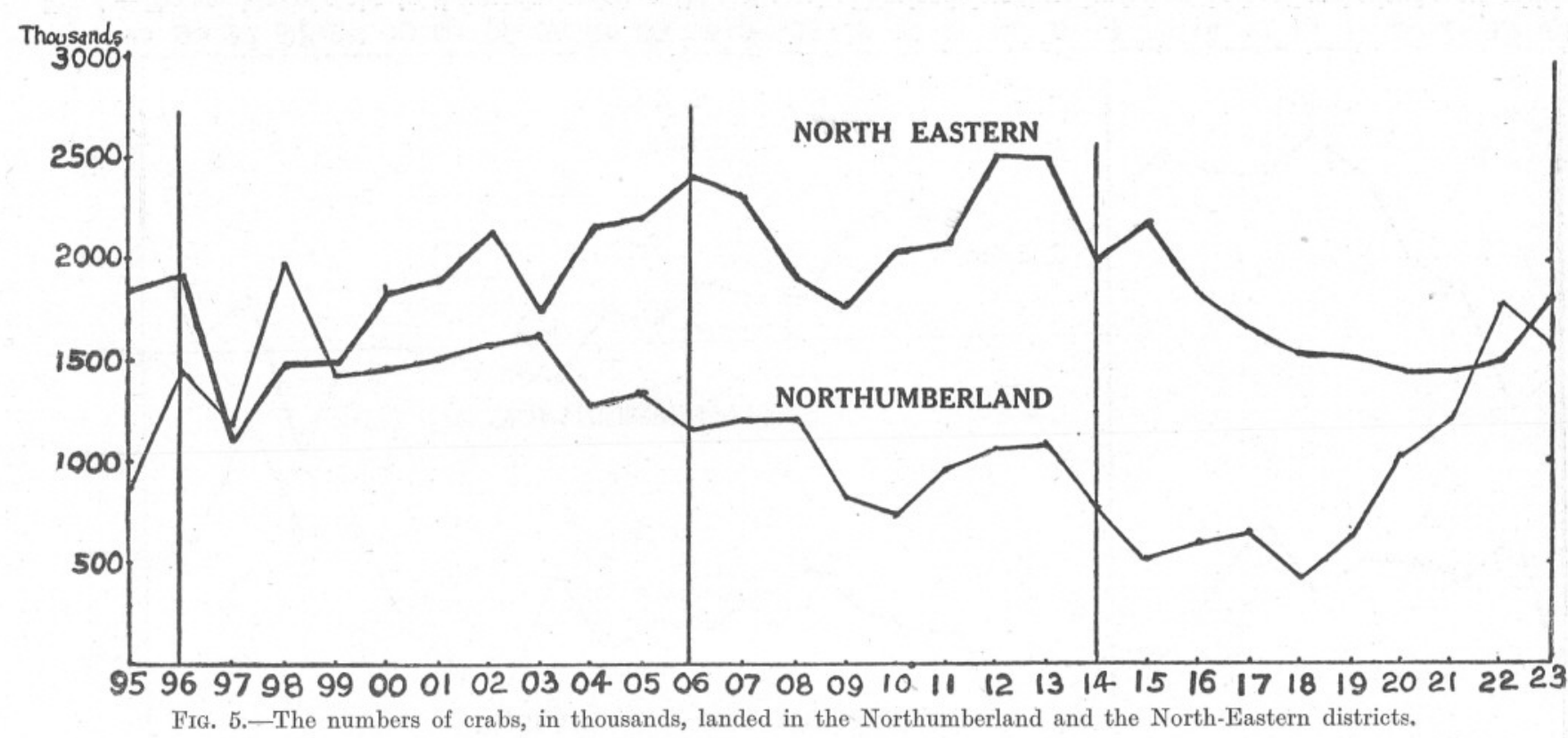




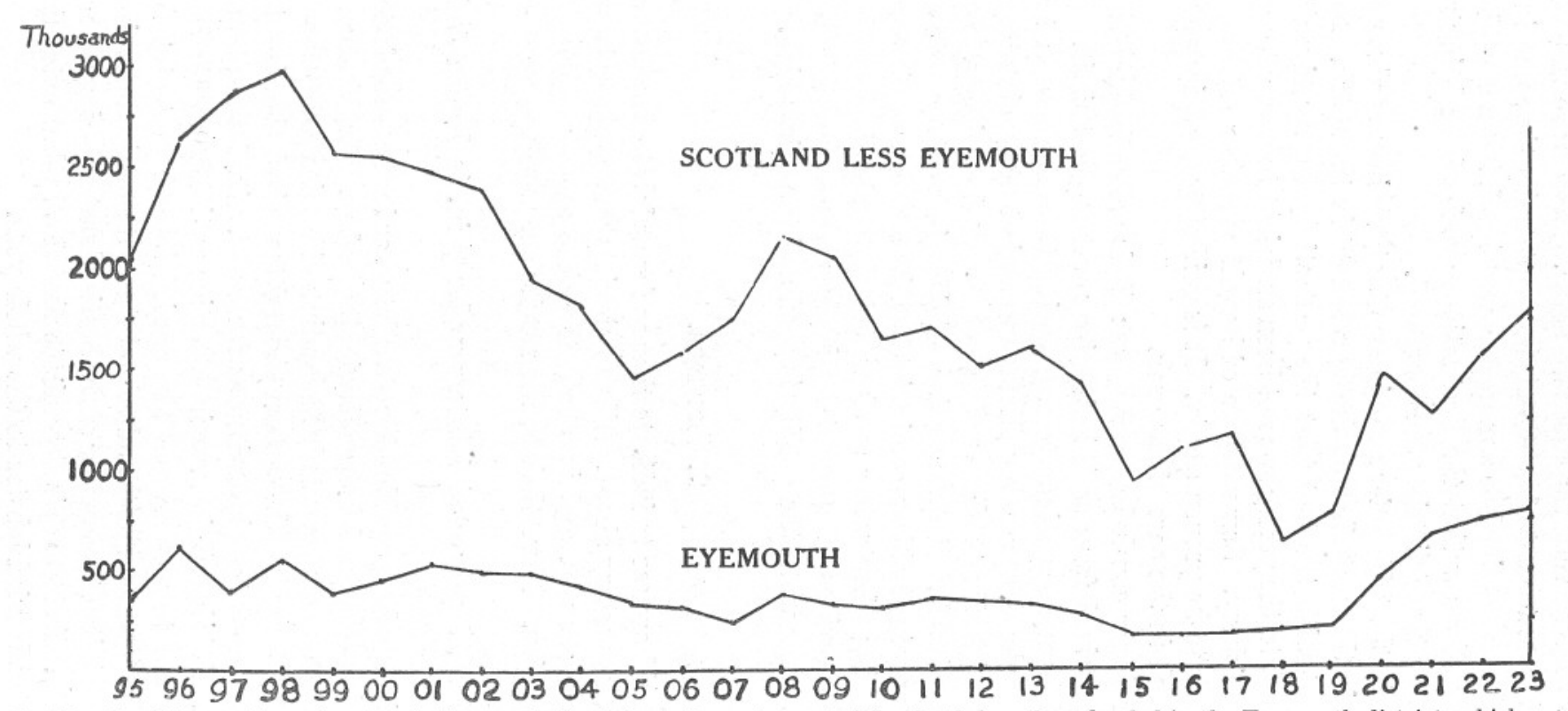

Fia. 6. - The numbers of crabs, in thousands, landed on the east coast of Scotland, less those landed in the Eyemouth district, which latter are also shown. 
It will be observed that the first two agree. Both have trebled their catches, and the east coast of Scotland shows generally the same features. The last two have remained at a more constant level, but a consideration of the figures will show that the fluctuations are far from being regular when the two southern districts are compared.

The figures in the table offer no evidence that the increased number of berried crabs in the north has produced a benefit in the south. But this is in agreement with the fact that the protection already given to the berried crab and to the young has not been sufficient to prevent a general decline in the fishery. Some degree of benefit probably follows, but it does not appear to be proven as yet. It is evidently more important to protect the adult in the case of the crab.

The former paper concluded as follows: It is acknowledged that the benefit to be derived from such legislation must reach a limit. But so long as the fishermen continue to fish during the open season the rest enjoyed during the close season will have the effect of keeping the population up to a high, if not always the same, level of efficiency. Seasonal variation is inevitable. The protection as given in Northumberland and in a different way in the Eastern district has the advantage of preventing destructive fishing when prices are low and the crabs liable to be poor in quality. It provides a larger catch with less labour, and the crabs are marketed at a time when the quality is good and the prices high.

\section{LOBSTER.}

Figure 7 would appear to indicate that so far as lobsters are concerned there is nothing to worry about. All the districts on the East Coast have improved conspicuously, and it would therefore appear superfluous to speak of protection. Nevertheless, the results are worth some degree of consideration.

The Act of 1877 protected lobsters under 8 in. in length and that was all.

The Committees along the English coast have, as in the case of the crab, attempted to improve the lobster fisheries by by-law. The Eastern Committee since 1895 have prevented the landing of berried lobsters and soft lobsters. In 1896 the North-Eastern Committee raised the size limit to 9 in. and introduced the close time as for crabs, viz. 1st September to 31st January. This legislation was in operation until 1920, when the close time was brought to an end and the berried lobster protected for the whole year. In 1899 the Northumberland Committee raised the size limit to $9 \mathrm{in}$. and prohibited the landing of the berried lobster during the months of April to July. In 1915 this Committee passed a by-law extending the protection of the berried lobster to the whole year. 
Thousands

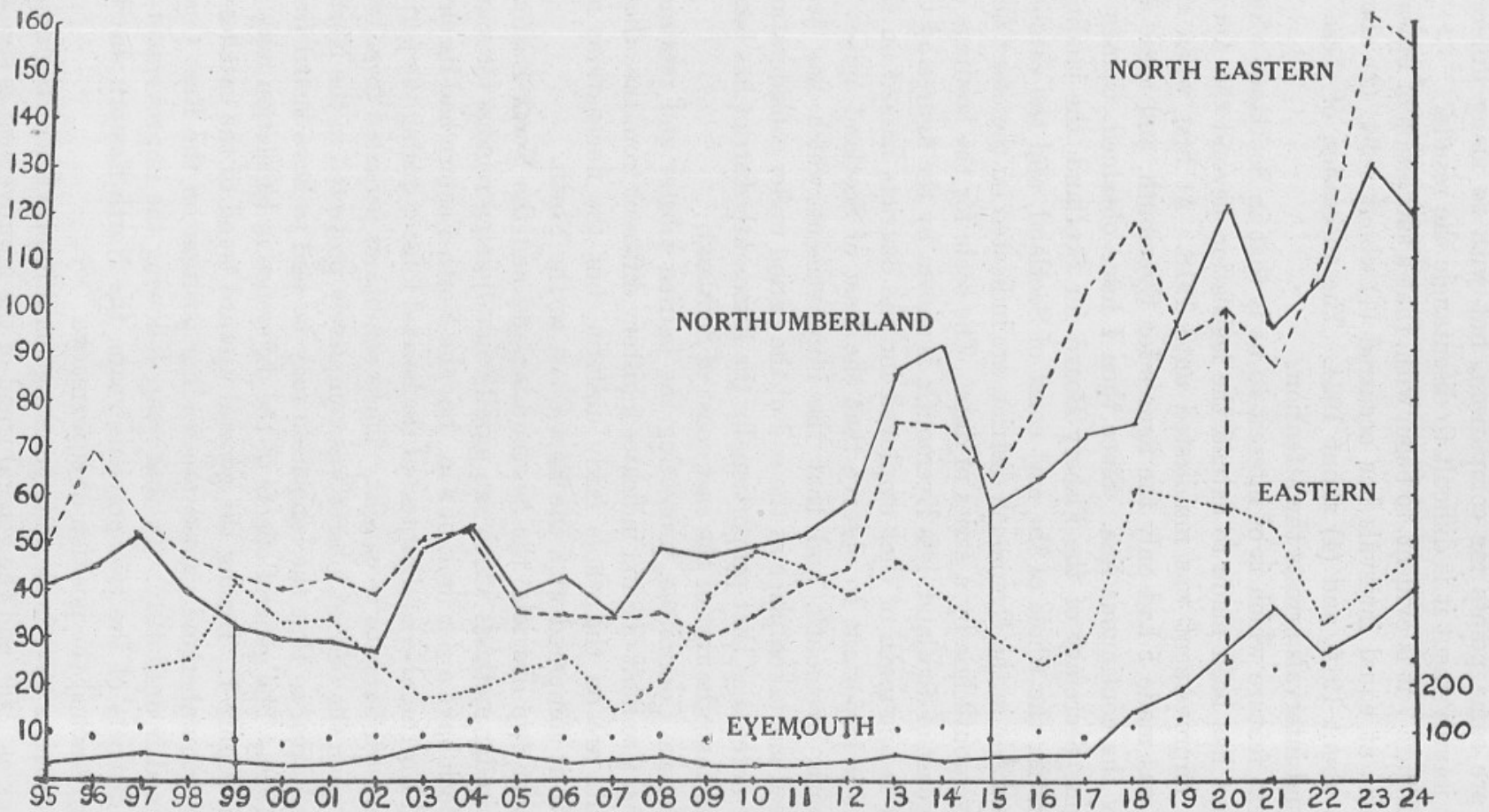

FIG. 7.-The numbers of lobsters, in thousands, landed in the Eyemouth, Northumberland, North-Eastern and Eastern districts. The dots in the lower part of the figure indicate on a tenth scale compared with the others the landings of lobsters on the east coast of Scotland, less those landed in the Eyemouth district. 
There are some points for comparison, but with so many different efforts at improvement it is difficult to disentangle the results.

From Figure 7 it is evident, to begin with, that a succession of upward fluctuations at equal intervals has occurred (1) about 1894, (2) about 1904, (3) about 1914, and (4) about 1924. The succession of these at about equal intervals arrests the attention.

The next feature which is of interest to us is that in Scotland, where no attempt has been made to extend the legislation beyond the Act of 1877, no improvement was manifested until 1918. At first when the diagram was made I had only the figures for Eyemouth, and these are shown by the continuous line. Since then I have obtained, thanks to the obliging Secretary of the Fishery Board for Scotland, the landings of lobsters for the whole of the east coast of Scotland, and the catches, less those made in the Eyemouth district, are indicated on the chart near to the Eyemouth line by a series of dots. The scale for the landings on the east coast of Scotland, less Eyemouth, is shown by the figures on the right: it is one-tenth of that employed for the districts named on the chart. It is important to observe that the East of Scotland agrees so closely with Eyemouth, and that the improvement which has been experienced has taken place at the end of the period under consideration. It will be noted also that proportionally the Eyemouth district has benefited more than the rest of the east coast of Scotland.

The Eastern Committee, protecting the berried lobster and retaining the original size limit of 8 in., indicates a history different from the others. The results are on the whole fairly uniform, but the fluctuations are peculiar to it compared with the East Coast to the North.

The other two districts, the Northumberland and the North-Eastern, tried dissimilar methods which ran parallel in adjoining regions for many years. Both have a size limit of 9 in., but the North-Eastern had its close time, and Northumberland protected the berried lobster during the period when it is most liable to be caught. These conditions persisted from 1899 to 1915 , when the berried lobster was completely protected in the Northumberland area, so that the legislation may be said to have lasted from 1899 to 1920 . The general effects of the difference in legislation may be seen from Figure 7. During the general upward trend of the catches in 1903-4 Northumberland gained the leading position on the East Coast and retained it until 1915. In that year, following the improvement in the two districts of the two previous years, the North-Eastern district once more reached the position of supremacy.

These districts have both undergone a general improvement beginning as far back as 1909, and the general trend of the improvement is similar. This and the history generally, as indicated in Figure 7, goes to show that the two districts are correlated. 
Marking experiments have been tried on the Northumberland coast on several occasions and the results have been presented in the reports of the Cullercoats Laboratory. The results did not show any definite sign of migration such as were obtained in the case of the crab. One female certainly was returned from a position ten miles north of the place of liberation. The want of evidence is probably due to two facts: (1) the experiments were made on too smale a scale, (2) the marked lobsters were for the most part berried and had therefore no occasion to migrate.

We have not any definite knowledge of a benefit on the contranatant side. But from the fact of the correlation of the two districts, and it is a correlation which is manifestly shared in by the east coast of Scotland, we feel that it is highly probable that the females about to be berried actually make a contranatant migration. The rise, notably in the Eyemouth district, following the marked increase of the population of lobsters in Northumberland, is interesting in this respect.

The experiments and the observations of the fishermen indicate that the lobster keeps more inshore, even in winter, and, probably, if it be shown that the females are contranatant, the migration of the mature lobster is not to so great a distance as the mature crab. The rest enjoyed then during the period when the close time of the North-Eastern Committee was in operation may have had some result. But the rest is already given generally by the habits of the fishermen who, in the colder months place their crab-pots in deep water to catch crabs.

The marking experiments showed incidentally that the catching power of the fishermen is great, a return of as many as 36 per cent being recorded in one experiment. The average catch during the last ten years in Northumberland was 93,414 lobsters, and of this number some 13 per cent would be berried, that is 12,000 . So that if a number near the borders of the district cross the boundary from the one to the other, and it is highly probable, the gain is a substantial one.

The larvæ are pelagic for about three weeks and are therefore liable to a considerable denatant migration. But it has been a matter of surprise to us that so few have been captured in our plankton nets. In spite of the large amount of netting which has been done for nearly thirty years on the Northumberland coast, both inshore and offshore, a very small number only has been recorded. They must be present in the shore waters in plenty, for if the population of lobsters on the coast includes some 40,000 berried lobsters and each furnishes, say, 40,000 larvæ, to say nothing of the larvæ borne by current into the area, large numbers of larvæ must prevail during the hatching season.

Wondering if we had fallen into some mistake as to the habits of the larvæ, I asked Mrs. Cowan to obtain one or two berried lobsters and to watch the larvæ carefully. She found, as we had observed before, that 
they were definitely pelagic and speedily died if they reached the bottom prematurely. The only conclusion we can arrive at, then, is that the larvæ are strong enough to evade or to swim out of the nets.

In spite of their swimming powers they are denatant, but because of the swimming powers probably not so much so as the crab larvæ. With this in mind I obtained the figures and attempted to show in 1914* that the near part of the district to the south of Northumberland was gaining from the improvement in Northumberland.

This discussion leads to the conclusion that the lobster larvæ are better able to avoid capture than those of the crab, and that the increased population on the East Coast has been due to a survival above the normal to adult size. But it is an increase which from its incidence is clearly associated with the protection which is given on the north-east coast of England to the berried lobster.

The general result in each case, that of the crab and lobster, is interesting and important; the demonstration that the coastal region is capable of supporting a very much larger population than in the past. And I think it will be conceded that the efforts at improvement in the one case by protecting the fishery from a season of destructive fishing and in the other by protecting the berried female have been justified.

* Report Dove Mar. Lab. New Ser., III, p. 77. 